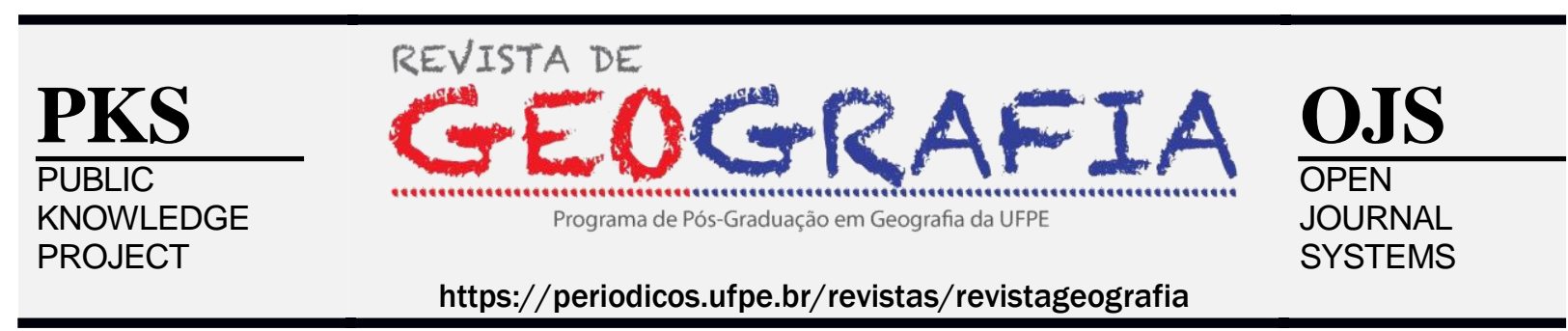

\title{
A INTERMEDIAÇÃO DAS RELAÇÕES INTERNACIONAIS ENTRE O BRASIL E A BOLÍVIA REALIZADA PELAS CIDADES-GÊMEAS DE GUAJARÁ-MIRIM (RONDÔNIA) E GUAYARAMERÍN (BENI)
}

\author{
Leonardo Luiz Silveira da Silva ${ }^{1}$, Alexandre Magno Alves Diniz ${ }^{2}$
}

\author{
${ }^{1}$ IFNMG-Campus Salinas. E-mail: leoluizbh@hotmail.com \\ ${ }^{2}$ Programa de Pós-Graduação em Geografia - Tratamento da Informação Espacial-PUC-MG. E-mail: \\ madiniz@gmail.com
}

Artigo recebido em 11/04/2019 e aceito em 25/11/2019

\begin{abstract}
RESUMO
Este artigo investiga duas cidades gêmeas dos confins territoriais do Brasil e da Bolívia. Em meio à paisagem amazônica, as cidades estudadas posicionam-se como espaços importantes da circulação. Afinal, neste estudo, partimos do pressuposto que as cidades-gêmeas constituem-se como nós importantes das redes transfronteiriças dos Estados. Deste modo, a partir de um trabalho de campo nas cidades-gêmeas de Guajará-Mirim (Rondônia) e Guayaramerín (Beni), foram levantados dados primários de diversos equipamentos urbanos que atestaram o status das mesmas de articuladoras de parcela das relações entre o Brasil e a Bolívia. Nesta pesquisa foram pesquisadas escolas, hospitais, hotéis, transportes e consulados das duas cidades-gêmeas. $\mathrm{O}$ trabalho aponta para uma relação de interdependência e complementariedade das áreas urbanas estudadas, que acontece, por sua vez, de forma assimétrica entre os diversos planos pesquisados. $\mathrm{O}$ artigo evidencia que, mesmo em uma era em que se aponta a excessiva porosidade dos limites internacionais, se faz necessária considerar a existência de soberanias em contraste. Afinal, é por meio das assimetrias nos espaços nacionais vizinhos que o limite se faz notar, clarificando as diferenças mais ou menos visíveis nos arranjos sociais.
\end{abstract}

Palavras-chave: Cidades-gêmeas; Brasil; Bolívia.

\section{THE INTERMEDIATION OF INTERNATIONAL AFFAIRS BETWEEN BRAZIL AND BOLIVIA CONDUCTED BY THE TWIN CITIES OF GUAJARÁ-MIRIM (RONDÔNIA) AND GUAYARAMERÍN (BENI)}

\begin{abstract}
This article investigates two twin cities of brazilian-bolivian territorial borders. Situated in the Amazonian landscape, the studied cities are positioned as important spaces of the circulation. After all, in this study, we assume that twin cities are important axis of the cross-border networks of States. Thus, from a local research in the twin cities of Guajará-Mirim (Rondônia) and Guayaramerín (Beni), primary data were collected of several urban equipments that attested the status of Brazil and Bolivia relationship articulators. In this research, schools, hospitals, hotels, transport and consulates of the two twin cities were surveyed. The work points to a relation of interdependence and complementarity of the studied urban areas, which happens, in turn, in an asymmetrical way among the several surveyed plans. The article shows that, even in an era in which the excessive porosity of international boundaries is pointed out, it is necessary to consider the existence of sovereignties in contrast. After all, it is through the asymmetries in the neighboring national spaces that the limit is noticed, clarifying the differences more or less visible in the social arrangements.
\end{abstract}

Keywords: Twin Cities; Brasil; Bolivia. 


\section{INTRODUÇÃO}

$\mathrm{O}$ trabalho em questão pretende apresentar alguns resultados de uma pesquisa de campo que compõem os requisitos de um estágio pós-doutoral em Geografia, pelo programa de pós-graduação em Tratamento da Informação Espacial da PUC-Minas. A pesquisa centrase nas relações entre o Brasil e a Bolívia articuladas pelas cidades-gêmeas de Guajará-Mirim (Brasil - Rondônia) e Guayaramerín (Beni - Bolívia). O trabalho não pretende apresentar o conjunto absoluto das relações, muitas das quais informais e de difícil mensuração. Objetiva buscar, por intermédio de investigação de dados primários provenientes de importantes equipamentos urbanos, tais como escolas, hospitais, transportes, hotéis e consulados, apontar em que medida Guajará-Mirim e Guayaramerín auxiliam nas relações entre o Brasil e a Bolívia. O método empregado nesta pesquisa se assemelha ao utilizado no trabalho que investigou a intermediação das relações entre o Brasil e a Bolívia intermediados pelas cidades-gêmeas de Brasiléia, Epitaciolândia (Acre - Brasil) e Cobija (Pando - Bolívia) (Silva, 2018).

As cidades-gêmeas são núcleos urbanos conurbados ou não que se posicionam na zona de fronteira de dois ou mais Estados. Sua posição geográfica permite que a mesma se apresente como um nó concentrador e dispersor de fluxos transfronteiriços, o que explica o seu papel estratégico. No passado, prevaleciam as preocupações praticamente exclusivas de segurança do território. Na contemporaneidade, o papel da segurança é dividido, em maior ou menor parcela, com o papel de cidades auxiliares da cooperação e integração dos países que as abrigam.

Tais cidades constituem-se como nós importantes de redes transfronteiriças, e, como foi dito, articulam fluxos que se concentram em sua posição geográfica e que se dispersam pelo território vizinho. Considerando o sentido associado entre poder, território e redes (Raffestin, 2011), as cidades-gêmeas auxiliam também na formação de fluxos que não são controlados pelos Estados, formando espaços de múltipla territorialidade.

As cidades-gêmeas estão inseridas em regiões fronteiriças. Partindo do pressuposto caráter polissêmico da fronteira, se faz necessário apontar que a mesma é entendida neste trabalho como as fronteiras dos Estados, que são, no sentido prático, áreas definidas pelas próprias entidades estatais de acordo com os seus interesses estratégicos (constituindo-se, na prática, como faixa de fronteira). 
As fronteiras dos Estados passaram por um verdadeiro processo de ressignificação desde a fundação da ordem vestfaliana. Outrora entidades mal definidas que abrigavam poderes estatais débeis e incapazes de exercer esplêndida territorialização no espaço, as fronteiras passaram por um inegável processo de fortalecimento. Este processo se explica, por sua vez, pelo entendimento por parte do Estado do seu valor estratégico, materializado no aperfeiçoamento dos instrumentos de territorialização e na concentração de políticas voltadas para o espaço fronteiriço. Contudo, a ordem pós Guerra Fria marcou uma nova significação da fronteira, que passou paulatinamente a ser porosa mediante a natureza dos fluxos transnacionais que marcam a contemporaneidade, ao ponto de alguns apostarem no fim dos territórios (Badie, 1995), em um mundo sem soberania (Badie, 1999), no fim dos EstadosNação (Ohmae, 1999) ou ainda do próprio fim da "geografia" (Virilio, 2007). Todas estas teses são ancoradas naquilo que Bauman (2001) chamou de "liquidez", referindo à natureza das modificações constantes e que impõem fluxos que não podem ser completamente bloqueados pelo Estado moderno, dentre os quais o migratório (Bauman, 2017). Fluxos incontroláveis que são causados em grande medida pela acentuação da compressão tempoespacial descrita por David Harvey (2004), ainda que, as alardeadas condições que intensificam a globalização não se apresentem, como nos alerta Milton Santos (2012) em seu livro manifesto, de forma homogênea dentre as diversas parcelas do espaço e quiçá entre os seus rincões.

São múltiplas as razões para o desacerto comparativo na evolução das características das fronteiras, destacando-se entre elas as diferenças entre as formas em que o Estado lida com a sua soberania, a capacidade dos mesmos de fazer valer a sua soberania nas áreas periféricas do seu território e até mesmo na própria falência estatal, que conduz os Estados ao status de Estado Falido (collapsed or failed states) (Fukuyama, 2005).

\section{ALGUNS ASPECTOS GEOGRÁFICOS E HISTÓRICOS DE GUAJARÁ-MIRIM}

Localizada no extremo oeste do estado de Rondônia, o município conta com 47.451 habitantes segundo estimativa para o ano de 2017 (IBGE, 2017), em contraste com os 41.656 registrados pelo Censo de 2010. Deste total, ainda segundo os dados do Censo 2010, 35.207 eram habitantes da área urbana do município, o que dimensiona a representatividade populacional da cidade de Guajará-Mirim. A cidade localiza-se fora da alça viária mais importante do estado de Rondônia, a BR-364, que conecta as cidades mais populosas do 
estado e se constitui como eixo preferencial de acesso aos estados do Acre, Amazonas e Mato Grosso. O seu sítio urbano, caracterizado pela monotonia topográfica (a partir de evidente aplainamento), sofre com as cheias do rio Mamoré, se dispondo de forma alongada acompanhando a BR-425, evitando se estender às margens do rio. Este quadro dá ao formato do sítio urbano a configuração de "espinha de peixe" (Santos, 2008), com poucas avenidas paralelas à BR-425 e com o predomínio de vias transversais.

Ainda que fundada em uma posição estratégica, junto ao limite territorial brasileiroboliviano, que é definido pelo rio Mamoré no trecho em questão, o valor da posição geográfica de Guajará-Mirim se deteriorou ao longo do século XX. Fundada a partir do espelhamento de um núcleo urbano mais antigo, o de Guayaramerín, na margem oposta do rio Mamoré, a cidade brasileira em questão viveu períodos econômicos importantes devido aos tempos áureos da borracha. Utilizado como ponto de referência para o cumprimento de um dos itens do acordo que conduziu o território do Acre à posse brasileira, o sítio urbano de Guajará-Mirim era a extremidade sul da ferrovia Mamoré-Madeira, que ligaria a cidade à capital estadual Porto Velho. A ferrovia em questão auxiliaria o escoamento da produção boliviana até Porto Velho e dali por via fluvial até o Oceano Atlântico, percurso fundamental para a Bolívia, que viu, por sua vez, o seu litoral ser subtraído por intermédio da Guerra do Pacífico, travada junto ao Chile (Gisbert et al., 2012; Cervo \& Bueno, 2012). Com o declínio da borracha no mercado internacional e com o avanço do modal rodoviário, a ferrovia Madeira-Mamoré passou a ser subutilizada, até ser abandonada por completo (Albuquerque \& Silva, 2014). O Eixo de desenvolvimento do estado, que até então era ditado pelo traçado da ferrovia, transferiu-se para a rodovia BR-364.

A cidade de Guajará-Mirim foi alvo, na década de 1990, de políticas territoriais especiais. Estas se enquadram no esforço do governo brasileiro para o fortalecimento de suas fronteiras e tiveram como alvo as cidades-gêmeas do arco norte. Nesse sentido, foram criadas as Áreas de Livre Comércio (ALCs). No sentido prático, as ALCs oferecem benefícios fiscais semelhantes aos da Zona Franca de Manaus no aspecto comercial. Os incentivos concentramse na isenção do Imposto sobre Produtos Industrializados (IPI) e do imposto sobre circulação de Mercadorias e Prestação de Serviços (ICMs).

\section{Quadro 1 - Cidades contempladas pelo regime das ALCs}

\begin{tabular}{|l|l|l|}
\hline Cidade & $\begin{array}{l}\text { Unidade da } \\
\text { Federação }\end{array}$ & Cidade-Gêmea \\
\hline
\end{tabular}


Revista de Geografia (Recife) V. 36, No. 3, 2019

\begin{tabular}{|c|c|l|}
\hline Boa Vista & Roraima & Não \\
\hline Bonfim & Roraima & Sim \\
\hline Guajará-Mirim & Rondônia & Sim \\
\hline Brasiléia & Acre & Sim \\
\hline Epitaciolândia & Acre & Sim \\
\hline Cruzeiro do Sul & Acre & Não \\
\hline Tabatinga & Amazonas & Sim \\
\hline Macapá & Amapá & Não \\
\hline Santana & Amapá & Não \\
\hline
\end{tabular}

Fonte: SUFRAMA, 2013

Como informa a tabela, nem todas as cidades de fronteira contempladas pelo regime das ALCs se enquadram na categoria de cidades gêmeas. Ainda assim, devido à relevância estratégica da área de fronteira, recebem o incentivo fiscal, possibilitando que o preço de inúmeros produtos industrializados internados em sua jurisdição seja mais competitivo frente à oferta observada no espaço internacional adjacente.

As cidades de fronteira, assim como qualquer núcleo urbano, são, em alguma medida, eixos articuladores das relações que se dispõem sobre o território no qual estão inseridas. Ao examinar o papel das cidades na contemporaneidade, Ash Amin (2002) escreve que as cidades não podem ser vistas como unidades territoriais restritas, mas por meio das múltiplas relações que por elas são engendradas. Pensando nesse sentido, os incentivos fiscais que atuam nas cidades localizadas no espaço fronteiriço buscam realçar o papel de articulação dos fluxos das redes que se dispõem no território, fazendo delas um posto avançado de territorialização do espaço nacional. As cidades-gêmeas da Região Norte são alvos preferenciais das políticas de incentivo do governo, dado a forte atuação das redes transfronteiriças sobre o seu espaço.

\section{ALGUNS ASPECTOS GEOGRÁFICOS E HISTÓRICOS DE GUAYARAMERÍN}

Situada no leste do departamento boliviano de Beni, Guayaramerín foi fundada em 1892 sob o nome de Puerto Palmira, em um importante momento da extração gomífera. Assim como a sua vizinha Guajará-Mirim, a cidade boliviana encontra-se em uma periferia territorial do seu país e é dotada de um sítio urbano alongado, de topografia aplainada, que acompanha uma via principal em detrimento do alongamento paralelo ao rio Mamoré. 
Configura-se assim a morfologia de espinha de peixe, ainda que um pouco desajustada devido à interferência de um aeroporto posicionado em uma diagonal frente ao principal eixo de circulação urbano.

O censo boliviano de 2012 contou 41.814 habitantes para o município de Guayaramerín (INE, 2012), sem a discriminação entre moradores da área rural e urbana. Tal montante representa $9,9 \%$ da população departamental, que registrou a cifra de 422.008 no mesmo recenseamento.

A cidade de Guayaramerín viveu durante muitos anos a expectativa de valorização de sua posição urbana, que poderia vir a ocorrer caso as tratativas posteriores ao Tratado de Petrópolis se consolidassem plenamente. Havia a expectativa que a linha férrea que ligou Guajará-Mirim a Porto Velho superasse o rio Mamoré, conectando a cidade de Guayaramerín não só ao espaço brasileiro, mas também a estação inicial da ferrovia, que seria na cidade de Riberalta. Esta cidade, por sua vez, trata-se de um importante núcleo urbano do departamento de Beni (contava 89.022 habitantes no recenseamento de 2012).

\section{ALGUMAS RELAÇÕES INTERMEDIADAS PELOS EQUIPAMENTOS URBANOS DAS CIDADES-GÊMEAS DE GUAJARÁ-MIRIM E GUAYARAMERÍN}

\section{Educacionais}

Existem dois tipos de interações educacionais muito distintas entre as duas cidades estudadas: àquela referente ao Ensino Médio e à outra referente ao Ensino Superior. Com a recente graduação em medicina aberta na UAB (Universidade Autônoma de Beni), um fluxo importante de estudantes brasileiros passou a atravessar diariamente o rio Mamoré, por meio das embarcações dos portos. Pelo fato de serem estudantes usufruem de um desconto substancial na passagem (da ordem de $50 \%$, ou 4 reais por travessia). O número de estudantes brasileiros matriculados na UAB é de 190 segundo o calendário acadêmico de 2017 (número que tende a aumentar pois o curso possui três anos de fundação).

No Ensino Fundamental e Médio foram consultadas as maiores escolas de Guayaramerín, totalizando 4.226 alunos. 


\section{Quadro 2: Alunado das escolas de Ensino Fundamental e Médio investigadas em}

Guayaramerín - Beni: ano letivo de 2017

\begin{tabular}{|c|c|}
\hline Escola consultada & Quantidade de alunos \\
\hline Mariscal Andrés de Santa Cruz & 488 \\
\hline San José Fe y Alegria & 515 \\
\hline Armando Mollinedo Bacarezza & 510 \\
\hline Manuel Antonio Ojopi & 501 \\
\hline Liceu nacional & 550 \\
\hline Alto de Alianza & 685 \\
\hline Carlos Loayza Beltrán & 521 \\
\hline \multicolumn{2}{|c|}{ Luis Anés Ortiz } \\
Total & 479 \\
\hline \multicolumn{2}{|c|}{ Fonte: Consulta aos sistemas internos dos estabelecimentos de Ensino }
\end{tabular}

O número de alunos computados foi expressivo, pois, representa aproximadamente $31,57 \%$ da população recenseada entre 6 e 19 anos pelo censo 2012 realizado pelo INE (Instituto Nacional de Estatística). Viu-se, neste número, o local (município) de nascimento do estudante. Foi possível constatar que, neste nível de ensino e na amostra levantada, somente 4 alunos são nascidos no Brasil.

Em Guajará-Mirim, a tendência se inverte. No Ensino Superior não se vê a participação de bolivianos, enquanto que no Ensino Médio e Fundamental é possível observar. Na UNIR (Universidade Federal de Rondônia) campus Guajará-Mirim, que registrou um total de 835 alunos matriculados em 2017, somente uma aluna possui naturalidade de Guayaramerín. No Ensino Médio e Fundamental, também em 2017, 26 estudantes tiveram a naturalidade ligada a algum município boliviano.

\section{Quadro 3: Alunado das escolas de Ensino Fundamental e Médio investigadas em}

Guajará-Mirim - RO: ano letivo de 2017

\begin{tabular}{|c|c|}
\hline Escola consultada & Quantidade de alunos \\
\hline Instituto Federal de Rondônia - IFRO & 159 \\
\hline Simon Bolívar & 449 \\
\hline Rocha Leal & 494 \\
\hline Irmã Celeste & 625 \\
\hline Paul Harris & 217 \\
\hline Alkindar Brasil de Arouca & 1.482 \\
\hline Paulo Saldanha & 634 \\
\hline Capitão Godoy & 460 \\
\hline Total & 4.520 \\
\hline
\end{tabular}

Fonte: Consulta aos sistemas internos dos estabelecimentos de ensino 
Quadro 4: As 10 principais naturalidades da rede educacional (Ensino Básico e superior) de Guajará-Mirim-RO em escolas selecionadas*

\begin{tabular}{|c|c|c|c|}
\hline Naturalidade & $\begin{array}{c}\text { Quantidade de } \\
\text { alunos }\end{array}$ & $\begin{array}{c}\text { Participação } \\
(\%)\end{array}$ & $\begin{array}{c}\text { Participação (\%) } \\
\text { excluído o volume de } \\
\text { Guajará-Mirim }\end{array}$ \\
\hline Guajará-Mirim-RO & 4.363 & 81,48 & Não se aplica \\
\hline Porto Velho-RO & 278 & 5,19 & 28,02 \\
\hline Costa Marques-RO & 117 & 2,18 & 11,79 \\
\hline Nova Mamoré-RO & 60 & 1,12 & 6,05 \\
\hline Não Informado & 59 & 1,10 & 2,82 \\
\hline Rio Branco-AC & 28 & 0,52 & 2,72 \\
\hline Ariquemes-RO & 27 & 0,50 & 2,72 \\
\hline Algum município boliviano & 27 & 0,50 & 2,12 \\
\hline Ouro Preto do Oeste-RO & 21 & 0,39 & 2,12 \\
\hline Ji-Paraná-RO & 21 & 0,39 & 64,31 \\
\hline Total & 5.001 & 93,37 & \\
\hline
\end{tabular}

*Fonte: Consulta aos sistemas internos dos estabelecimentos de ensino citados no quadro III.

Esta complexa realidade numérica está pronta para ser investigada. Uma vez que os fluxos educacionais encontraram este cenário, qual seria a razão para:

- Um número expressivo de brasileiros (190) estarem matriculados em Guayaramerín no Ensino Superior e o mesmo não se observar no Ensino Básico (4 alunos na expressiva amostra)?

- Um irrisório registro de 1 aluna boliviana matriculada no Ensino Superior brasileiro enquanto 26 alunos desta mesma nacionalidade estavam matriculados em escolas brasileiras?

A atração dos equipamentos de Ensino Superior, sobretudo a oferta do curso de medicina a preços próximos a 400 reais mensais, juntamente com uma demanda reprimida pelo curso em universidades públicas no Brasil parecem explicar parte desta realidade. $\mathrm{O}$ Ensino Básico, incapaz de atrair um grande número de brasileiros à Bolívia, parece fazer o caminho contrário, sendo mais atrativo em equipamentos brasileiros. Já o Ensino Superior no Brasil, talvez pela crença da qualidade do ensino das instituições bolivianas, não é capaz de atrair bolivianos, como se viu no solitário registro de uma naturalidade ligada a este país. São questões que podem ser aprofundadas em estudos posteriores. 


\section{Hospitalares}

Em Guayaramerín foram levantados os dados do Hospital Maternal de janeiro a julho de 2018. Este foi o período possível para o levantamento, já que os dados dos períodos anteriores estavam organizados por ordem alfabética em pastas em numerosas prateleiras do almoxarifado. Assim, seriam necessárias a organização e separação de fichas de pacientes de mais de duas décadas. Os dados de janeiro a julho de 2018, por sua vez, ainda não havia sido inseridos nas prateleiras em ordem alfabética. $\mathrm{O}$ número de pacientes que consultaram o hospital no período foi de 1.203. Destes, 8 possuíam naturalidade de municípios brasileiros.

O Hospital Geral de Guayaramerín apresentavam as fichas de pacientes completamente desorganizadas, espalhadas pelas prateleiras sem critério algum. Ainda que exista um sistema contendo dados digitalizados sobre os pacientes, este não revela a naturalidade do mesmo. A informação da naturalidade, assim como aconteceu no Hospital Materno, estão todas presentes nas fichas de atendimento ao paciente. Por isso não foi possível mensurar a presença brasileira no hospital. Contudo, sabe-se que ela existe, à medida que a cirurgia oftalmológica neste hospital sabidamente atende aos brasileiros, como atestam as instruções em português presentes nos corredores da instituição.

Por outro lado, encontramos maior facilidade no levantamento de dados no lado brasileiro. Ainda que a informação que procurávamos estava somente disponível em fichas de atendimento, as mesmas estavam organizadas por período. Deste modo, foi possível consultar as naturalidades dos atendidos nos hospitais Bom Pastor, Perpétuo Socorro e em um centro de atendimento às pessoas com enfermidades psiquiátricas. Foram registrados 7.585 atendimentos em 2017, sendo que no hospital Perpétuo Socorro, foi levantada somente um amostra do ano, com atendimentos nos meses de janeiro e julho (pois o número de atendimentos de um ano é estimado em 27.000, o que demandaria muito tempo para o registro das informações).

Do total dos pacientes registrados nas fichas dos hospitais consultados, 216 tinham a naturalidade de algum município boliviano. No que diz respeito ao uso dos equipamentos de saúde em 2017, podemos crer que este número é bem maior, afinal, o levantamento total dos dados do Hospital Perpétuo Socorro podem nos conduzir a números bem expressivos. Somente em janeiro, 98 bolivianos foram atendidos, enquanto que em junho se registra 73 . 
Considerando uma média mensal igual a 85,5 pacientes bolivianos, podemos ter um número próximo a 1000 atendimentos durante o ano.

Quadro 5: As 10 principais naturalidades dos pacientes atendidos em Guajará-MirimRO no ano de 2017 em dados selecionados*

\begin{tabular}{|c|c|c|c|}
\hline Naturalidade & $\begin{array}{c}\text { Quantidade de } \\
\text { pacientes }\end{array}$ & $\begin{array}{c}\text { Participação } \\
(\%)\end{array}$ & $\begin{array}{c}\text { Participação (\%) } \\
\text { excluído o volume de } \\
\text { Guajará-Mirim }\end{array}$ \\
\hline Guajará-Mirim-RO & 5.175 & 68,23 & Não se aplica \\
\hline Porto Velho-RO & 382 & 5,04 & 15,85 \\
\hline Não Informado & 249 & 3,28 & 10,33 \\
\hline Costa Marques-RO & 232 & 3,06 & 9,63 \\
\hline Algum município boliviano & 216 & 2,85 & 8,96 \\
\hline Nova Mamoré-RO & 142 & 1,87 & 5,89 \\
\hline Ji-Paraná-RO & 53 & 0,70 & 2,20 \\
\hline Rio Branco-AC & 49 & 0,65 & 2,03 \\
\hline Manaus-AM & 34 & 0,45 & 1,41 \\
\hline Jaru-RO & 33 & 0,44 & 1,37 \\
\hline Total & 6.565 & 86,57 & 57,67 \\
\hline
\end{tabular}

* Os dados são referentes à totalidade dos pacientes atendidos no Hospital Bom Pastor e na clínica de patologia psiquiátrica da prefeitura - CAPES. Soma-se a estes o volume de pacientes atendidos em janeiro e junho de 2017 do Hospital Perpétuo Socorro.

Fonte: Consulta aos sistemas internos dos estabelecimentos de saúde

Deste modo, pelo menos no que diz respeito ao comportamento do atendimento em grandes equipamentos de saúde, pode se ter uma ideia da interação transfronteiriça de saúde, que parece ser ainda mais intensa do que os fluxos educacionais. Deve se levar em conta que o fluxo educacional se estabelece, em grande medida, como pendular, ao passo que esta não parece ser, a priori, um comportamento geral dos fluxos de saúde. Faz-se necessário uma investigação complementar na saúde de Guayaramerín, para que o número comparado de pacientes diminua sua assimetria (1.203 a 7.585 a favor de Guajará-Mirim). Uma solução para atenuar o problema da assimetria dos dados seria a complementação da informação em Guayaramerín com dados de clínicas particulares. Com os dados aqui apresentados, é de se sugerir que bolivianos buscam mais o atendimento médico em Guajará-Mirim do que brasileiros em Guayaramerín.

\section{Dados da hotelaria}


Por intermédio dos dados da hotelaria, retirados das fichas de entrada dos hóspedes, podemos averiguar a sua procedência, estabelecendo noções preciosas sobre o fluxo de pessoas. Foram cinco hotéis investigados em cada cidade. Infelizmente, devido à inconsistência das fichas que não se encontram digitalizadas, os períodos examinados não são exatamente simétricos, mas concentram-se, em sua totalidade, em diversos fragmentos temporais dentro do ínterim compreendido por janeiro de 2017 e junho de 2018.

Quadro 6: Hotéis investigados nas cidades gêmeas de Guayaramerín (BOL) e GuajaráMirim (BRA)

\begin{tabular}{|c|c|c|}
\hline Município & Guayaramerín-BOL & Guajará-Mirim-Brasil \\
\hline \multirow{4}{*}{ Hotéis investigados } & Hotel Santana & Hotel Mini Estrela \\
\cline { 2 - 3 } & Hotel Sucre & Jamaica Hotel \\
\cline { 2 - 3 } & Hotel Asaí & Pakaas Palafitas Lodge \\
\cline { 2 - 3 } & Hotel Funf & Tropical Hotel \\
\cline { 2 - 3 } & Hotel Balneário São Carlos & Pousada Guajará \\
\hline
\end{tabular}

Em Guayaramerín foram computados 3.342 quartos reservados, com 94 procedências não declaradas. Destes, extraídos os não declarados, temos 234 (7,2\%) registraram procedência municipal brasileira. Em Guajará-Mirim, o desleixo quanto à organização dos dados dos hotéis foi percebido notoriamente. Poucos hotéis tinham as fichas registradas, e muitas das quais dotadas de informação incompleta, o que nos levou a um número de 1.573 quartos reservados, dos quais 283 com procedência não declarada, fazendo com que os destinos válidos totalizassem 1.290 ocorrências. Destas, 51 apresentaram procedência em algum município boliviano (4\%) dos registros válidos (excluídos àqueles que não foram declarados).

\section{Quadro 7: As 10 principais procedências dos hóspedes atendidos em Guayaramerín}

(BOL) e Guajará-Mirim (BRA) em hotéis selecionados

\begin{tabular}{|c|c|c|c|c|c|}
\hline $\begin{array}{c}\text { 10 principais } \\
\text { procedências } \\
\text { municipais de } \\
\text { Guayaramerín } \\
\text { (BOL) }\end{array}$ & $\begin{array}{c}\text { Quantidade } \\
\text { registrada }\end{array}$ & $\begin{array}{c}\text { \% } \\
\text { Válido* }\end{array}$ & $\begin{array}{c}\text { 10 principais } \\
\text { procedências } \\
\text { municipais de } \\
\text { Guajará-Mirim } \\
\text { (BRA) }\end{array}$ & $\begin{array}{c}\text { Quantidade } \\
\text { registrada }\end{array}$ & $\begin{array}{c}\text { Válido* } \\
\text { Trinidad-Beni }\end{array}$ \\
\hline Riberalta-Beni & 706 & 21,74 & Rio Branco-AC & 82 & 6,36 \\
\hline La Paz-La Paz & 604 & 19,89 & Guajará-Mirim-RO & 54 & 4,2 \\
\hline Silva e Diniz, 2019
\end{tabular}


Revista de Geografia (Recife) V. 36, No. 3, 2019

\begin{tabular}{|c|c|c|c|c|c|}
\hline $\begin{array}{c}\text { Santa Cruz- } \\
\text { Santa Cruz }\end{array}$ & 336 & 10,34 & Ji-Paraná-RO & 47 & 3,6 \\
\hline $\begin{array}{c}\text { Cochabamba- } \\
\text { Cochabamba }\end{array}$ & 222 & 6,8 & Riberalta (Bolívia) & 27 & 2,1 \\
\hline $\begin{array}{c}\text { Brasil - } \\
\text { Descrição não } \\
\text { municipal }\end{array}$ & 134 & 4,1 & Ariquemes-RO & 26 & 2,0 \\
\hline Porto Velho-RO & 80 & 2,5 & Cacoal-RO & 18 & 1,4 \\
\hline $\begin{array}{c}\text { Nueva } \\
\text { Esperanza-Beni }\end{array}$ & 37 & 1,1 & São Paulo-SP & 15 & 1,2 \\
\hline Cobija-Pando & 30 & 0,9 & Jaru-RO & 13 & 1,0 \\
\hline San Joaquin-Beni & 27 & 0,8 & Nova Mamoré-RO & 13 & 1,0 \\
\hline Acumulado & 3.036 & 93,47 & Acumulado & 1.035 & 80,23 \\
\hline
\end{tabular}

Ainda que os registros hoteleiros possam nos informar diferentes quadros no arranjo das redes urbanas nos dois lados da fronteira, fica evidenciada uma situação relativamente equilibrada nos fluxos transfronteiriços que buscam hospedagem nos dois municípios investigados.

\section{Transportes}

Até mesmo pela dificuldade de superação do rio Mamoré concomitante a ausência de ponte, os transportes conectados entre as duas cidades estão restritos ao modal fluvial e ao transporte intermodal rodoviário-fluvial. Além das embarcações que transportam pessoas, inúmeros barcos conduzem mercadorias. Diariamente, inclusive, registra-se a travessia de caminhões brasileiros rumo à Guayaramerín, por meio de balsa, como registra a Figura 1. 


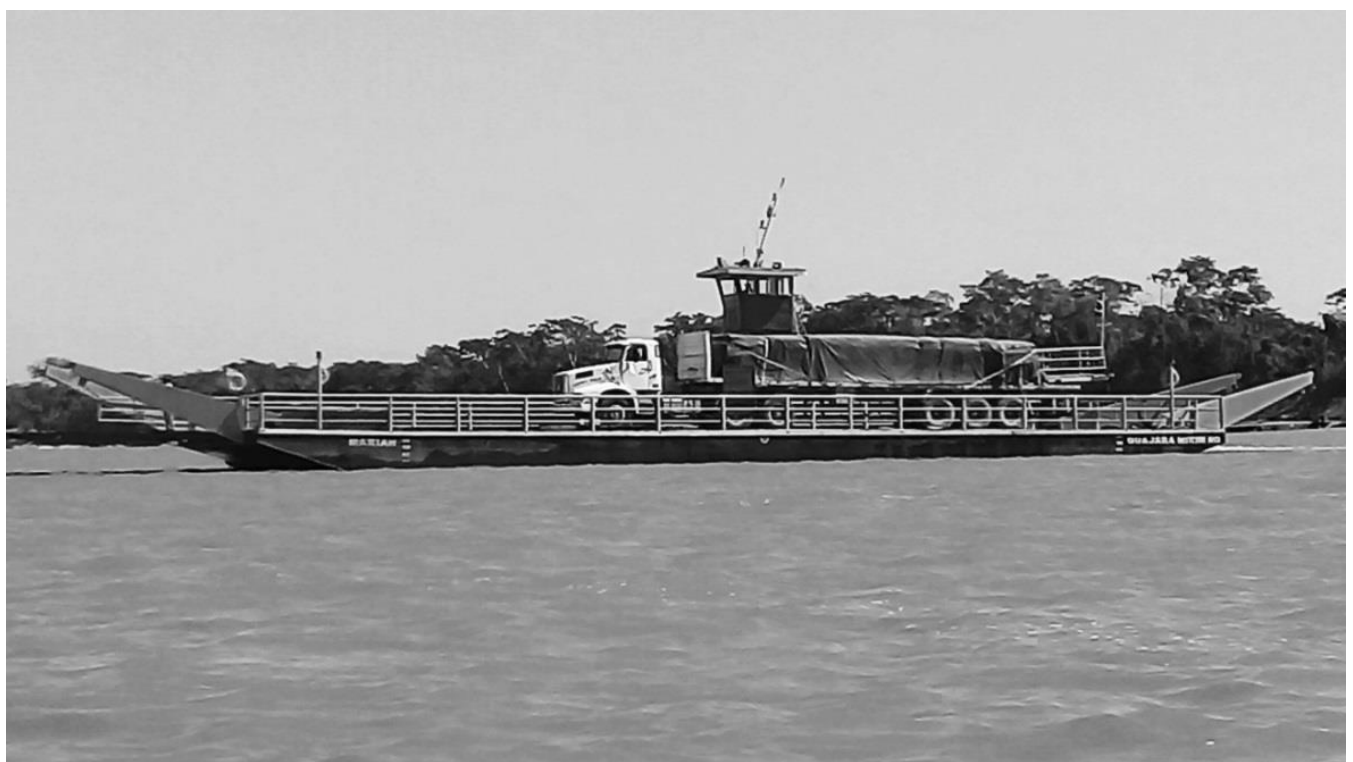

Figura 1: Caminhão brasileiro sendo conduzido por meio de balsa para Guayaramerín-BOL Figure 4: Brazilian truck being driven by ferry to Guayaramerín-BOL

Diariamente atravessam o rio Mamoré um volume estimado de 3.600 pessoas com direção às duas cidades-gêmeas estudadas. Esta estimativa se baseia na mensuração da travessia que realizamos no ponto de embarque e desembarque de pessoas, que registrou entre 6:00 e 19:00 horas do dia 25 de julho de 2018 (quarta-feira) 1.553 indivíduos atravessando no sentido Guajará-Mirim-Guayaramerín e 1.459 no sentido inverso. O equilíbrio entre esses números sugere expressiva travessia pendular, com motivações diversas. Para um quadro realístico das motivações e da pendularidade, sugerimos pesquisa específica sobre a travessia do rio Mamoré.

\section{Consulado}

Foram consultados dados do consulado brasileiro em Guayaramerín e do consulado boliviano em Guajará-Mirim. Os dados buscados foram o tipo de serviço realizado pelos dois consulados no ano de 2017. Os dados dos consulados revelam notoriamente um aspecto fortemente relacional das duas comunidades fronteiriças. O número expressivo de vistos concedidos pelo consulado Boliviano atesta a quantidade de brasileiros que buscam a travessia do Mamoré rumo ao país vizinho, indicando, inclusive, uma permanência mais longa (com o intuito de estudar, trabalhar ou mesmo fixar residência). No caso do consulado brasileiro, o número de vistos concedidos foi inexpressivo. Contudo, sabe-se que a Polícia Federal brasileira fornece vistos aos bolivianos. Os seus dados, contudo, não puderam ser extraídos. Aproveitamos a oportunidade para alertar aos pesquisadores que, quanto aos dados 
primários (ausentes em sistemas publicizados) da Polícia Federal, é de se esperar uma extrema burocratização. Recomenda-se um contato com bastante antecedência para a extração dos mesmos.

\section{Quadro 8: Os serviços realizados pelos consulados boliviano em Guajará-Mirim e} brasileiro em Guayaramerín no ano de 2017

\begin{tabular}{|c|c|c|c|}
\hline $\begin{array}{c}\text { Serviços prestados } \\
\text { pelo consulado boliviano } \\
\text { em Guajará-Mirim }\end{array}$ & $\begin{array}{l}\text { Quantidade } \\
\text { registrada }\end{array}$ & $\begin{array}{c}\text { Serviços prestados } \\
\text { pelo consulado } \\
\text { brasileiro em } \\
\text { Guayaramerín }\end{array}$ & $\begin{array}{l}\text { Quantidade } \\
\text { registrada }\end{array}$ \\
\hline Certidão de Nacionalidade & 49 & $\begin{array}{c}\text { Legalização de } \\
\text { documentos }\end{array}$ & 771 \\
\hline Certidão de nascimento & 138 & Vistos & 2 \\
\hline Autenticações & 181 & Passaportes & 4 \\
\hline Vistos & 2.009 & $\begin{array}{c}\text { Certificados de } \\
\text { nascimentos }\end{array}$ & 10 \\
\hline Certidão de Moradia & 4 & Matrícula consular & 468 \\
\hline Atestado de Óbito & 4 & \multirow[b]{2}{*}{ Outros } & \multirow[b]{2}{*}{6} \\
\hline $\begin{array}{c}\text { Ingresso de veículo de } \\
\text { Turismo }\end{array}$ & 31 & & \\
\hline $\begin{array}{c}\text { Bolivianos presos em } \\
\text { Rondônia }\end{array}$ & 20 & Brasileiros presos no Beni & 27 \\
\hline Total & 2.436 & Total & 1.288 \\
\hline
\end{tabular}

Fonte: Dados fornecidos pelos consulados organizados pelos autores

O significativo número das matrículas consulares demonstra a quantidade mínima de brasileiros que moram em Guayaramerín. A matrícula consular é um cadastramento do morador brasileiro no exterior junto ao consulado de sua jurisdição. Com esta matrícula, o atendimento ao brasileiro fica mais ágil, personalizado e menos burocratizado. Estima-se, contudo, um número maior de brasileiros morando em Guayaramerín, contando, inclusive, com àqueles que não se interessam em passar suas informações ao poder público por estar em uma situação de restrição legal.

\section{CONSIDERAÇÕES FINAIS}

O status de cidade-gêmea já confere à urbe, de antemão, certo grau de internacionalização de suas relações. No caso das cidades-gêmeas estudadas, as relações 
bilaterais se realçam, evidenciando importantes conexões em diversos segmentos, reveladas, por sua vez, pela investigação de alguns dos seus equipamentos urbanos. Outrossim, evidencia-se a ocorrência das relações bilaterais de forma assimétrica entre os diversos planos analisados: educacional, hospitalar, da hotelaria, dos transportes e consulados. Estas diferenças ilustram relações de complementariedade entre as duas cidades e outras simetrias existentes nas relações entre os países, regiões e sub-regiões as quais Guajará-Mirim e Guayaramerín estão inseridas.

Os dados levantados ajudam ainda a reforçar a hipótese de que as cidades-gêmeas se constituem como importantes nós das redes transfronteiriças, o que ressalta, a partir de um viés analítico geopolítico, a sua posição estratégica e a necessidade do Estado de estabelecer políticas diferenciadas para o seu espaço de influência.

\section{REFERÊNCIAS BIBLIOGRÁFICAS}

AMIN, Ash. (2002). Spatialites of globalization. Environment and Planning A, London, Vol. 34, pag. $385-399$.

ALBUQUERQUE, Hebert Lins de; SILVA, Josué da Costa. (2014). Estrada de ferro Madeira Mamoré em Nova Mamoré: sentimentos territoriais em face à globalização. Londrina: Geographia Opportuno Tempore, V.1, N.2, p.34-51.

BADIE, Bertrand. (1999). Um mundo sem soberania: os Estados entre o artifício e a responsabilidade. Lisboa: Instituto Piaget..

BADIE, Bertrand. (1995) O fim dos territórios: Ensaio sobre a desordem internacional e sobre a utilidade social do respeito. Lisboa: Instituto Piaget, 1995.

BAUMAN, Zygmunt. (2001). Modernidade Líquida. Rio de Janeiro: Zahar. BAUMAN, Zygmunt. (2017) Estranhos à nossa porta. Rio de Janeiro: Zahar. CERVO, Amado Luiz; BUENO, Clodoaldo. (2012) História da Política Exterior do Brasil. Brasília: Editora Universidade de Brasília.

FUKUYAMA, Francis. (2005) Construção de Estados. Rio de Janeiro: Rocco.

GISBERT, Carlos D. Mesa; FIGUEROA, José de Mesa; GISBERT, Teresa. (2012). Historia de Bolívia. La Paz: Editorial Gisbert.

IBGE, Instituto Brasileiro de Geografia e Estatística. Censo 2010. Disponível em: http://www.censo2010.ibge.gov.br/sinopse/index.php?uf=12\&dados=0

INE, Instituto Nacional de Estatística. Ficha Resumén Censo población e Vivenda 2012. Disponível em http://censosbolivia.ine.gob.bo/censofichacomunidad/

OHMAE, Kenichi. (1999) O fim do Estado-Nação. Rio de Janeiro: Campus.

RAFFESTIN, Claude. (2011). Por uma geografia do poder. São Paulo: Khedyr.

SANTOS, Milton. (2008). Manual de Geografia Urbana. São Paulo: Edusp.

SANTOS, Milton. (2012). Por uma outra globalização. Rio de Janeiro: Record.

SILVA, Leonardo Luiz Silveira da. (2018). O papel das cidades gêmeas de Brasiléia, Epitaciolândia e Cobija na intermediação das relações entre o Brasil e a Bolívia. Belo Horizonte: PUC-Minas. 
Revista de Geografia (Recife) V. 36, No. 3, 2019

SUFRAMA, Áreas de Livre Comércio, Manaus, disponível em http://www.suframa.gov.br/invest/zona-franca-de-manaus-alc.cfm Acesso em 17 de julho de 2015.

VIRILIO, Paul. (2007). Speed and Politics. Los Angeles: MIT Press. 